\title{
Atmospheric Environment Fabrication of Composite Films by Ethanol Catalytic Combustion and Its Use as Counter Electrodes for Dye-Sensitized Soar Cells
}

\author{
Xiaoping Zou and Cuiliu Wei \\ Research Center for Sensor Technology, Beijing Key Laboratory for Sensor, Ministry of Education Key Laboratory for \\ Modern Measurement and Control Technology, and School of Applied Sciences, Beijing Information Science and Technology University, \\ Jianxiangqiao Campus, Beijing 100101, China \\ Correspondence should be addressed to Xiaoping Zou; xpzou2005@gmail.com
}

Received 26 January 2014; Accepted 31 March 2014; Published 16 April 2014

Academic Editor: Li Song

Copyright (c) 2014 X. Zou and C. Wei. This is an open access article distributed under the Creative Commons Attribution License, which permits unrestricted use, distribution, and reproduction in any medium, provided the original work is properly cited.

The composite films which consist of amorphous carbon, carbon nanotube, and iron nanoparticles were prepared by ethanol catalytic combustion in atmospheric environment. The as-prepared composite films have good electrocatalytic activity and high conductivity which is due to their particular structure. The efficiency of the composite films based dye-sensitized soar cells (DSSCs) is closed to that of the Pt based one. Most importantly, the DSSC employing the composite films presents a higher FF than those of Pt based solar cell. In addition, it is a simple method for mass production of composite films counter electrode (CE) which is expected to reduce the cost of fabricating DSSCs.

\section{Introduction}

Since the report by O'Regan and Grätzel in 1991 [1], DSSCs have been regarded as promising devices for energy applications because of their advantages of low cost, ease of manufacture, and a relatively high photo-to-current conversion efficiency [2]. Moreover, the solar energy conversion efficiency of DSSCs with a ruthenium sensitizer and Pt counter electrode reaches $13.1 \%$ [3].

Counter electrode serves to transfer electrons from external circuit to triiodide and iodine in the redox electrolyte. Pt has been widely used as the counter electrode in DSSCs. Although Pt exhibits excellent catalytic activity for triiodide reduction and good electric conductivity, it is extremely expensive. Therefore, some nanosized carbon materials, such as hard carbon spherule [4], carbon nanotubes [5], mesoporous carbon [6], and ordered multimodal porous carbon [7], have been investigated extensively as counter electrode to replace the FTO/Pt electrode. However, the application of composite films which consist of amorphous carbon, carbon nanotube, and iron nanoparticles as counter electrode in
DSSCs has not been reported yet. Herein, the composite films were prepared by ethanol catalytic combustion in atmospheric environment. The as-prepared composite films as the counter electrode exhibit a good photovoltaic performance of DSSCs.

\section{Experimental}

2.1. Fabrication of Composite Film CEs. The preparation of composite electrode was conducted in the ethanol catalytic combustion (ECC) process. A small amount of thiophene was added to $100 \mathrm{~mL}$ anhydrous alcohol and then we added right amount of ferrocene to the solution which poured into the alcohol lamp at last. In this experiment, FTOs were employed as substrate which were fixed on the small lift then placed in the flame. The distance between the FTOs and the alcohol lamp wick was $6 \mathrm{~cm}$. After several seconds, the composite films were obtained on FTOs.

2.2. Assembly of DSSCs. The clean FTO was treated with $40 \mathrm{mM} \mathrm{TiCl}_{4}$ aqueous solution at $70^{\circ} \mathrm{C}$ for $30 \mathrm{~min}$. Then the 


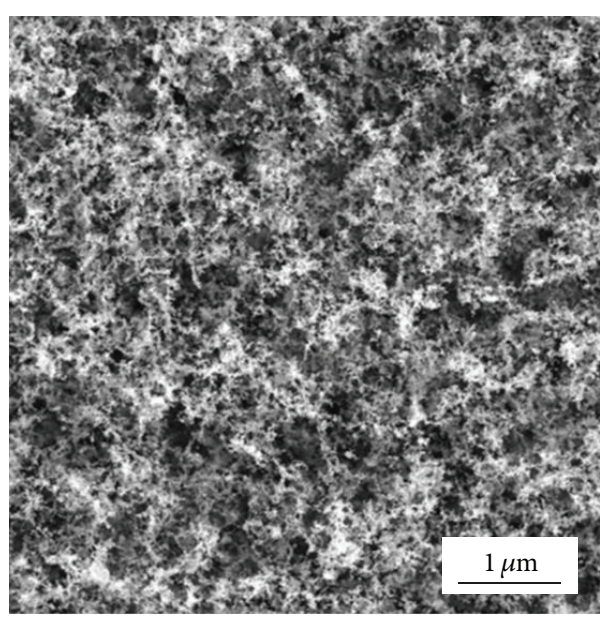

(a)

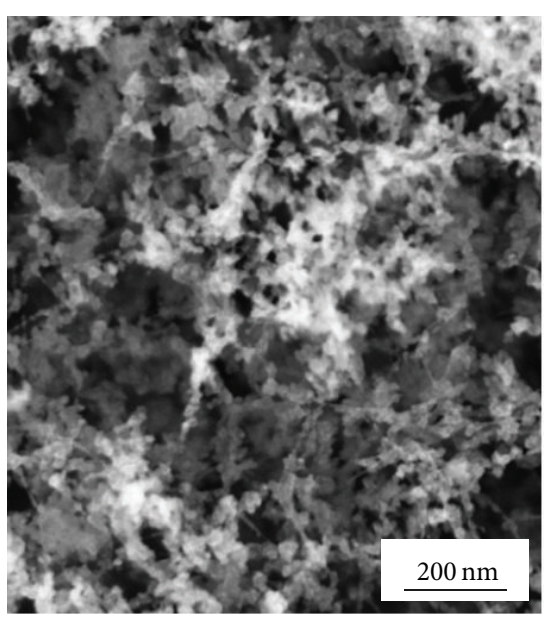

(b)

FIGURE 1: The typical SEM images of the film grown on the FTO; (a) and (b) are the low magnification image and high magnification image of the composite film, respectively.

$\mathrm{TiO}_{2}$ was coated on the FTO substrates by screen printing technique, followed by sintering at $450^{\circ} \mathrm{C}$ for $30 \mathrm{~min}$. The thickness of the $\mathrm{TiO}_{2}$ film was about $6.6 \mu \mathrm{m}$ which was controlled by the times of the screen printing technique. The $\mathrm{TiO}_{2}$ film was annealed at $450^{\circ} \mathrm{C}$ for $30 \mathrm{~min}$ and then was soaked into the $\mathrm{TiCl}_{4}$ aqueous solution with the concentration of $0.2 \mathrm{M}$ at $70^{\circ} \mathrm{C}$ for $30 \mathrm{~min}$. Following annealing for $30 \mathrm{~min}$ at $450^{\circ} \mathrm{C}$, the $\mathrm{TiO}_{2}$ film was cooled to $80^{\circ} \mathrm{C}$ and then immersed into a solution of the dye of cis-di (thiocyanato)-N-N ${ }^{\prime}$-bis (2,2' -bipyridyl-4-carboxylic acid- $4^{\prime}$ tetrabutylammonium carboxylate) ruthenium (II) (N-719) overnight. To prepare FTO/Pt electrode, the Pt catalyst was deposited on the FTO glass by coating with a drop of $\mathrm{H}_{2} \mathrm{PtCl}_{6}$ solution with repetition of the heat treatment at $450^{\circ} \mathrm{C}$ for $30 \mathrm{~min}$. The electrolyte was $\mathrm{LiI}(0.5 \mathrm{M}), \mathrm{I}_{2}(0.05 \mathrm{M}), 1$-propy 1-2, 3-dimethylimidazolium iodide (DMP, 0.3 M), and 4ter butylpyridine (4-TPB, $0.3 \mathrm{M})$ in an acetonitrile solution which was introduced into the cell gap between the anode and counter electrode. The active area of the cell was $0.25 \mathrm{~cm}^{2}$.

2.3. Characterization and Measurements. The morphologies of the composite films were characterized using the scanning electron microscopy (SEM, Zeiss ULTRA 55) and transmission electron microscopy (TEM, JEOL 2100). The composition of the as-prepared films was analyzed by the energy dispersive X-ray spectra (EDX, Zeiss ULTRA 55), Raman spectroscopy (Renishaw 2000), and thermogravimetric analysis (TGA, SDIA8H).

Electrochemical impedance spectroscopy (EIS) measurements were recorded using electrochemical workstation with bias DC voltage of $-0.6 \mathrm{~V}$ over the frequency range of $0.1 \mathrm{~Hz}$ to $100 \mathrm{kHz}$. The incident photo-to-current conversion efficiency (IPCE) was measured by using a lab-made IPCE setup in institute of plasma physics. The photocurrentvoltage (I-V) curves were measured by the electrochemical workstation under an illumination of xenon lamp. The irradiance is $100 \mathrm{~mW} / \mathrm{cm}^{2}$ which is measured by a radiometer
(FZ-A, Photoelectric Instrument Factory of Beijing Normal University).

\section{Results and Discussion}

Figures 1 and 2 show the typical SEM and TEM images of the composite films, respectively. The SEM shows that the composite film is made up of nanoparticles and nanotube. From the TEM, we can see clearly the structure of the carbon nanotube, metal nanoparticles, and amorphous carbon. Moreover, we can see that the metal nanoparticles are wrapped in the surface of nanotube and the amorphous carbon.

For further analysis, we have characterized the composite films by Raman spectroscopy. Figure 3 shows that the $\mathrm{G}$-band $\left(1586.4 \mathrm{~cm}^{-1}\right)$ is much higher than its D-band $\left(1339 \mathrm{~cm}^{-1}\right)$ which reveals that the composite films have a high graphitization degree. Moreover, there are some peaks in 0 to $400 \mathrm{~cm}^{-1}$ named radial breathing vibration mode (RBM) which shows that the composite films contain singlewalled carbon nanotubes. Figure $3(\mathrm{~b})$ is the enlarged of RBM in Figure 3(a). From Figure 3(b), we can see that the frequency of the peaks is $209 \mathrm{~cm}^{-1}, 222 \mathrm{~cm}^{-1}, 230 \mathrm{~cm}^{-1}$, and $268 \mathrm{~cm}^{-1}$ which correspond to the diameter of single-walled carbon nanotubes at $1.12 \mathrm{~nm}, 1.05 \mathrm{~nm}, 1.02 \mathrm{~nm}$, and $0.87 \mathrm{~nm}$, respectively.

Figure 4 shows the EDX spectrum of the composite films. From the EDX spectrum, we can see that the sample consists of $\mathrm{C}, \mathrm{O}, \mathrm{Fe}$, and a very small amount of Sn. The existence of $\mathrm{Sn}$ is probably from the FTO.

In order to determine the content of carbon nanotube, iron nanoparticles, and amorphous carbon, we have analyzed the composite films by TGA (Figure 5). The TGA carve declines slowly from $20^{\circ} \mathrm{C}$ to $191.7^{\circ} \mathrm{C}$ which corresponds to the reduction of water of the composite films. In this process, the weight of the sample is loss of $5 \%$. When the temperature 


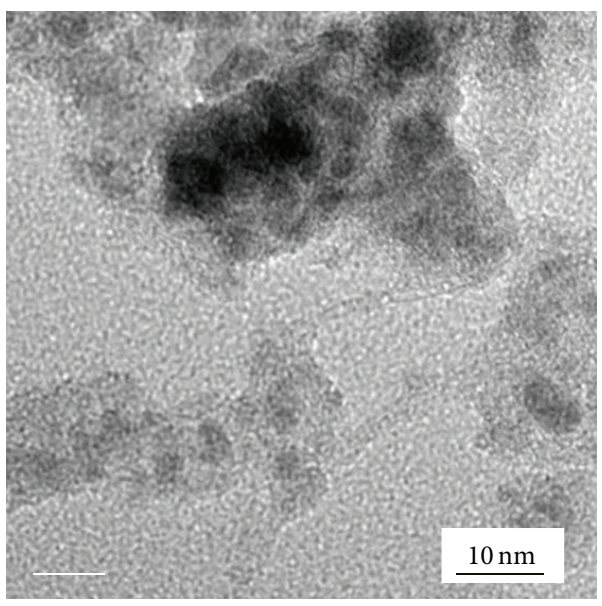

(a)

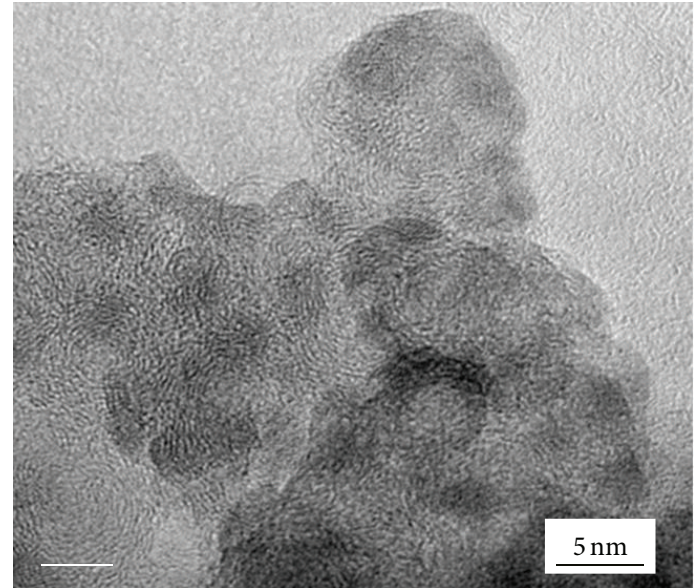

(b)

FIGURE 2: The typical TEM images of the film grown on the FTO; (a) and (b) are the low magnification image and high magnification image of the composite film, respectively.

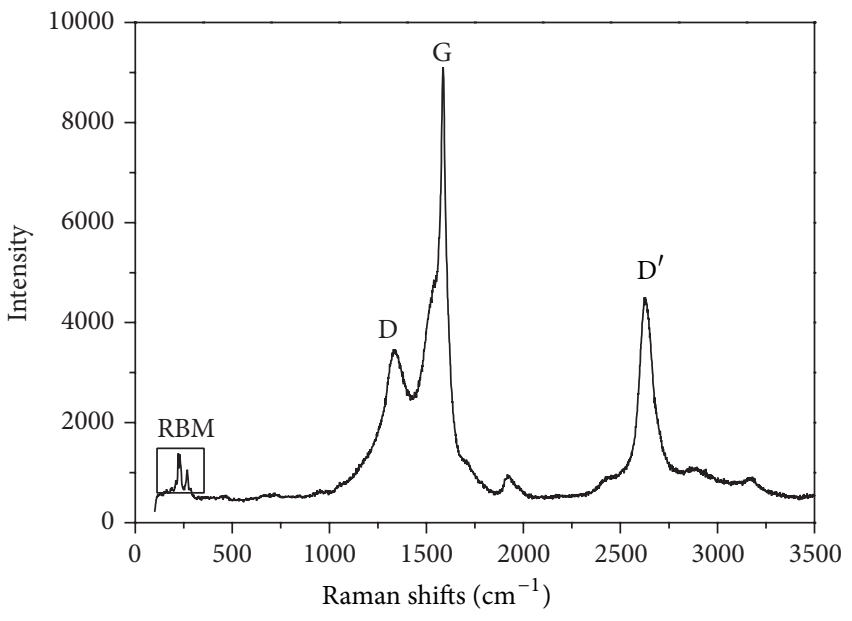

(a)

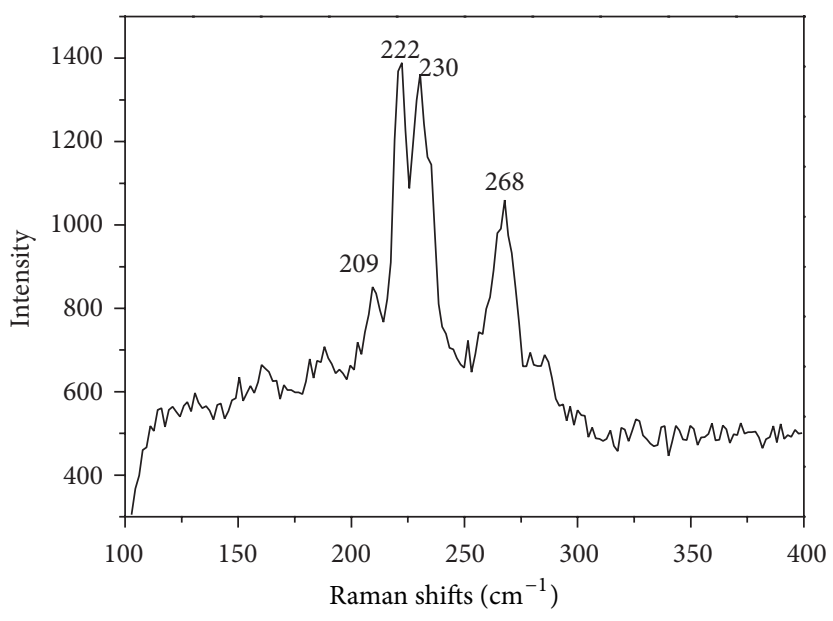

(b)

FIGURE 3: (a) is Raman spectrum of the composite films in Figure 1; (b) is the enlarged of RBM in (a).

is more than $254.68^{\circ} \mathrm{C}$, the slope of TGA carve increases which shows that the amorphous carbon reduces. When the temperature is from $330^{\circ} \mathrm{C}$ to $509.2^{\circ} \mathrm{C}$, the slope of the TGA carve continues to increase and the weight loss of the sample is sped up; the mass loss is about $34.4 \%$. When the temperature is more than $509.2^{\circ} \mathrm{C}$, the slope of the TGA carve reduces till $758.3^{\circ} \mathrm{C}$ which corresponds to the reduction of carbon nanotube. In this process, the mass loss is about 5.5\%. The rest of the sample is iron and iron oxide which is about $54.16 \%$.

IPCE characteristics of the DSSCs with composites films counter electrode and Pt are shown in Figure 6. The maximum IPCE value at $540 \mathrm{~nm}$ of the DSSCs with composite films counter electrode is approximately $72 \%$, and those of the DSSC with the Pt are 76.3\%. Adsorbed spectra of the DSSCs with composite films counter electrode are lower than those of the DSSC with the Pt in the range 380-650 $\mathrm{nm}$ and both the adsorbed spectra change almost unanimously at longer wavelengths above $650 \mathrm{~nm}$. In general, the IPCE of the DSSCs with composite films counter electrode is comparable to that of the DSSC with FTO/Pt counter electrode.

To investigate the electrochemical activity of the asprepared composite films, electrochemical impedance spectra (EIS) were measured. Figure 7 shows the equivalent circuit for the DSSCs, where $R 1$ is the ohmic serial resistance mainly related to the FTO glass, CPE1 and CPE2 are the capacitance of electrical double layer, respectively, $R 2$ is the chargetransfer resistance of the counter electrode and electrolyte, $R 3$ is the recombination resistance of the anode electrode and the electrolyte, and Ws is the Warburg impedance of the electrolyte. As shown in Figure 7, $R 1$ can be determined by the 


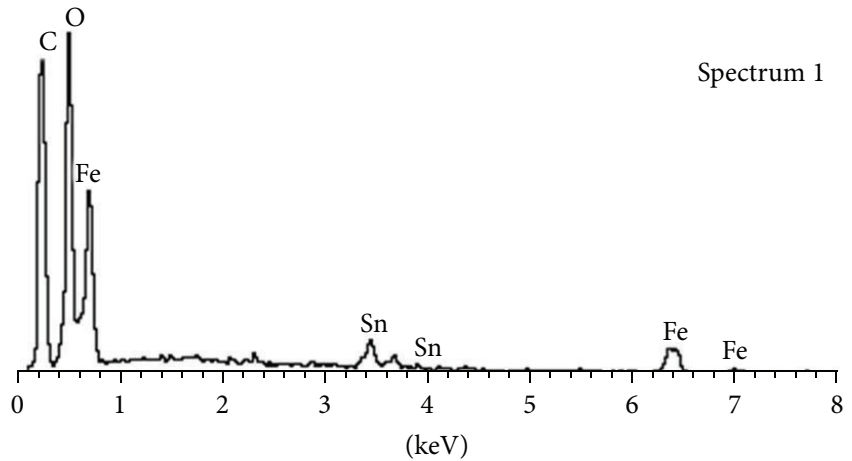

FIGURE 4: The EDX spectrum of the composite film corresponding to the Figure 1.

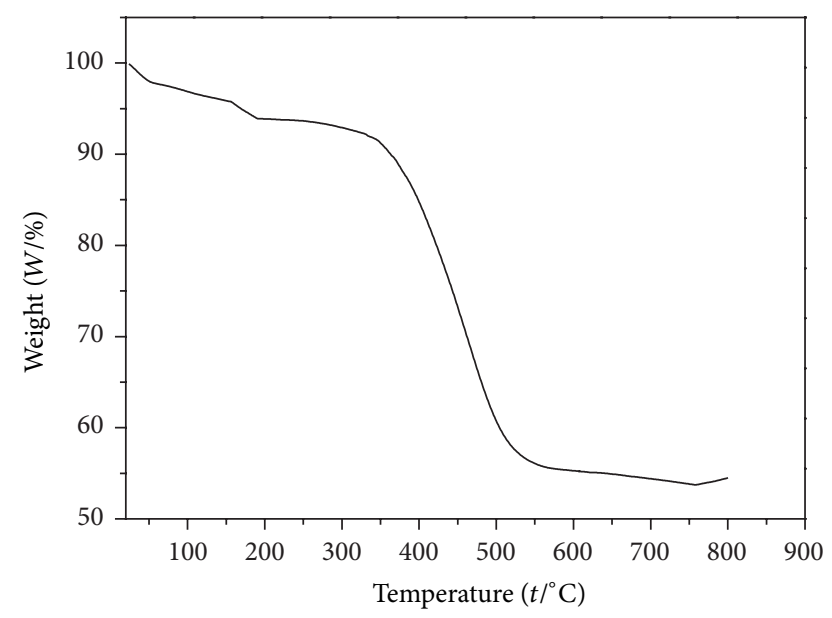

Figure 5: The TGA curve of the composite films at $20^{\circ} \mathrm{C}$ to $800^{\circ} \mathrm{C}$.

impedance at high frequency of around $100 \mathrm{kHz}$, while $R 2$ and $R 3$ are derived from the semicircles in the high and middle frequency ranges, respectively, through fitting the plots with Z-VIEW software. The resistance elements $R 1, R 2, \mathrm{CPE} 1$, and Ws values are summarized in Table 1. Obviously, the chargetransfer resistance of the composite films is much lower than Pt. It means that the composite films have an excellent electrocatalytic activity and high conductivity which is likely attributed to the big effective contact area of the composite films and the electrolyte and the high conductivity of the carbon nanotube. The composite electrodes exhibit larger CPE1 values than that of the Pt, which means that the composite electrodes have longer electronic life [8]. However, the Ws values of the composite electrode is larger which is likely due to the thicker layer along the composite electrode, as compared with the Ws in a thin layer of the smooth FTO/Pt electrode $[9,10]$.

Figure 8 shows photocurrent-voltage characteristics of DSSCs using the composite electrodes and the Pt electrode as the counter electrode and the corresponding parameters are listed in Table 2.

As we can see in Table 2, as reference, the DSSCs with a typical FTO/Pt as counter electrode has an open-circuit

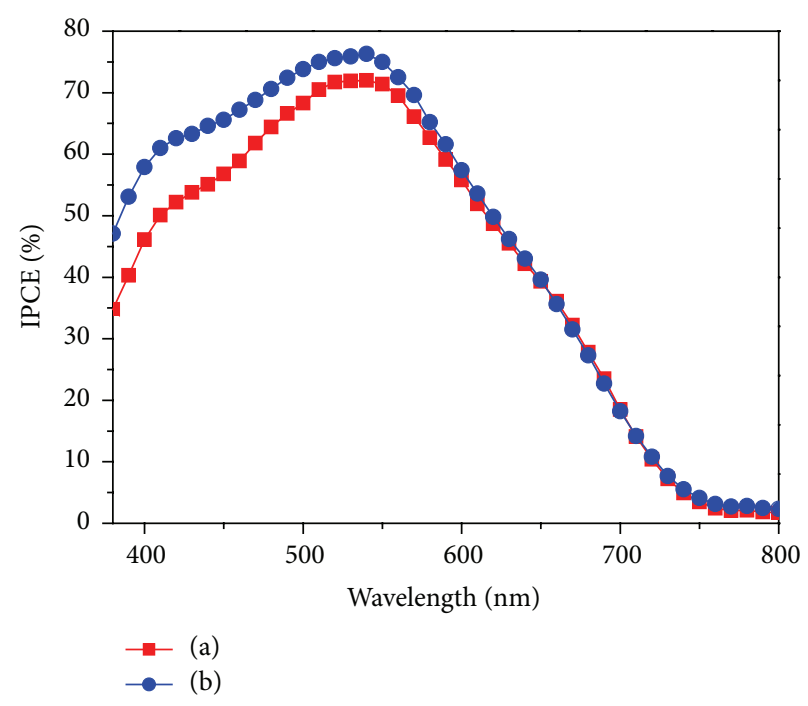

FIGURE 6: IPCE characteristics of the DSSCs with composite films counter electrode (a) and $\mathrm{Pt}(\mathrm{b})$.

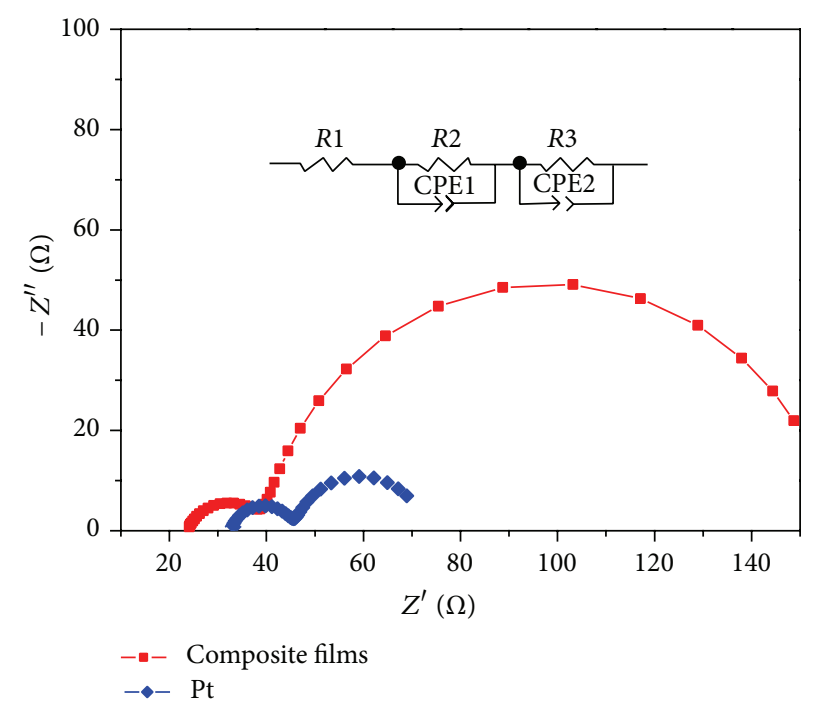

FIGURE 7: EIS spectra of the DSSCs with the composite films counter electrode and Pt electrode. The cells were measured with the frequency range of $100 \mathrm{mHz}$ to $100 \mathrm{kHz}$.

voltage $\left(V_{\mathrm{OC}}\right)$ of $0.8072 \mathrm{~V}$, short-circuit current density $\left(J_{\mathrm{SC}}\right)$ of $12.91 \mathrm{~mA} \mathrm{~cm}^{-2}$, fill factor (FF) of 0.5316 , and conversion efficiency $(\eta)$ of $5.54 \%$. When composite electrode is used as the counter electrode, the $V_{\mathrm{OC}}, J_{\mathrm{SC}}, \mathrm{FF}$, and $\eta$ of DSSC can reach as high as $0.7940 \mathrm{~V}, 10.70,0.5603$, and $4.76 \%$, respectively. Compared with Pt electrode, the $V_{\mathrm{OC}}, J_{\mathrm{SC}}$, and $\eta$ are lower, but the FF is larger, which should be attributed to the effective contract area of the electrolyte and the composite films counter electrode.

\section{Conclusions}

In summary, the composite films were obtained by ethanol catalytic combustion in atmospheric environment and were 


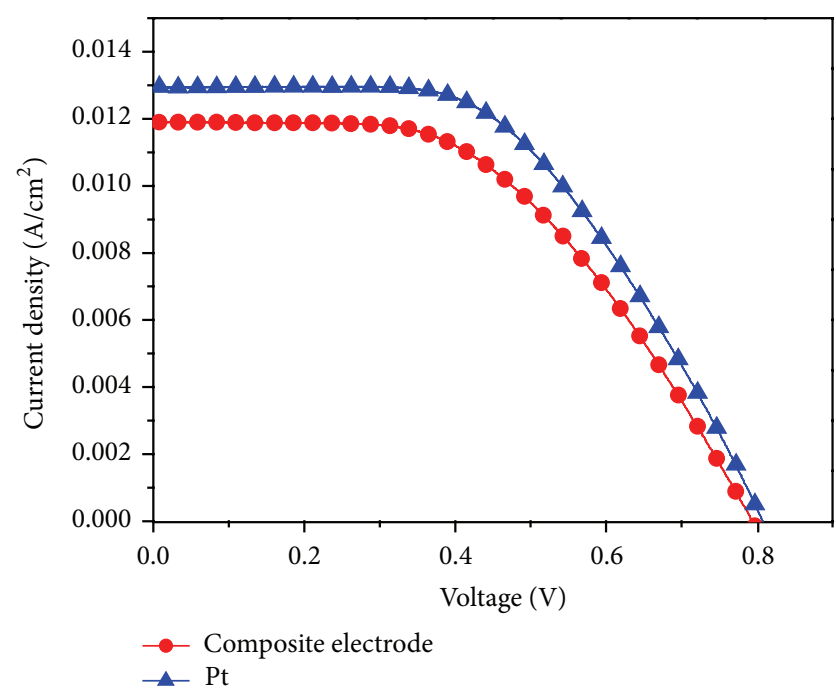

FIGURE 8: I-V characteristic curves of DSSCs with the composite films and $\mathrm{Pt}$, respectively.

TABLE 1: R1, R2, and CPE1 values of DSSCs with the composite films and Pt.

\begin{tabular}{lcccc}
\hline Counter electrode & $R 1(\Omega)$ & $R 2(\Omega)$ & $\mathrm{CPE} 1(\mu \mathrm{F})$ & Ws $(\Omega)$ \\
\hline Composite films & 24.17 & 6.27 & 27.36 & 16.68 \\
$\mathrm{Pt}$ & 32.57 & 12.97 & 26.41 & 14.3 \\
\hline
\end{tabular}

TABLE 2: I-V parameters of these cells in Figure 8.

\begin{tabular}{lcccc}
\hline Counter electrode & $V_{\mathrm{OC}}(\mathrm{V})$ & $J_{\mathrm{SC}}\left(\mathrm{mA} / \mathrm{cm}^{2}\right)$ & $\mathrm{FF}$ & $\eta(\%)$ \\
\hline Composite electrode & 0.7940 & 10.70 & 0.5603 & 4.76 \\
$\mathrm{Pt}$ & 0.8072 & 12.91 & 0.5316 & 5.54 \\
\hline
\end{tabular}

used directly as the counter electrode for DSSCs. It is demonstrated that the photovoltaic performance of the DSSCs with the composite films as the counter electrode is excellent and compared to that of the DSSCs with FTO/Pt counter electrode, which is attributed to their good electrocatalytic activity and high conductivity. A detailed understanding of the relationship between the electron transfer and electrolyte diffusion needs further investigation.

\section{Conflict of Interests}

The authors declare that there is no conflict of interests regarding the publication of this paper.

\section{Acknowledgments}

This work was partially supported by Key Project of Beijing Natural Science Foundation (3131001), Key Project of Natural Science Foundation of China (91233201 and 61376057), Key Project of Beijing Education Committee Science and Technology Plan (KZ201211232040), State 863 Plan of MOST of PR China (2011AA050527), Beijing National Laboratory for Molecular Sciences (BNLMS2012-21), State Key Laboratory for New Ceramic and Fine Processing of Tsinghua University (KF1210), Key Laboratory for Renewable Energy and Gas Hydrate of Chinese Academy of Sciences (y207ka1001), Beijing Key Laboratory for Sensors of BISTU (KF20131077208), and Beijing Key Laboratory for photoelectrical measurement of BISTU (GDKF2013005).

\section{References}

[1] B. O’Regan and M. Grätzel, "A low-cost, high-efficiency solar cell based on dye-sensitized colloidal $\mathrm{TiO}_{2}$ films," Nature, vol. 353, pp. 737-740, 1991.

[2] M. K. Nazeeruddin, R. Humphry-Baker, P. Liska, and M. Grätzel, "Investigation of sensitizer adsorption and the influence of protons on current and voltage of a dye-sensitized nanocrystalline $\mathrm{TiO}_{2}$ solar cell," The Journal of Physical Chemistry B, vol. 107, pp. 8981-8987, 2003.

[3] A. Yella, H.-W. Lee, H. N. Tsao et al., "Porphyrin-sensitized solar cells with cobalt (II/III)-based redox electrolyte exceed 12 percent efficiency,' Science, vol. 334, no. 6056, pp. 629-634, 2011.

[4] Z. Huang, X. Liu, K. Li et al., "Application of carbon materials as counter electrodes of dye-sensitized solar cells," Electrochemistry Communications, vol. 9, no. 4, pp. 596-598, 2007.

[5] C. S. Chou, R. Y. Yang, M. H. Weng, and C. I. Huang, "The applicability of SWCNT on the counter electrode for the dyesensitized solar cell," Advanced Powder Technology, vol. 20, pp. 310-317, 2009.

[6] G. Wang, W. Xing, and S. Zhuo, "Application of mesoporous carbon to counter electrode for dye-sensitized solar cells," Journal of Power Sources, vol. 194, no. 1, pp. 568-573, 2009.

[7] S.-Q. Fan, B. Fang, J. H. Kim et al., "Ordered multimodal porous carbon as highly efficient counter electrodes in dye-sensitized and quantum-dot solar cells," Langmuir, vol. 26, no. 16, pp. 13644-13649, 2010.

[8] J. Bisquert and V. S. Vikhrenko, "Interpretation of the time constants measured by kinetic techniques in nanostructured semiconductor electrodes and dye-sensitized solar cells," Journal of Physical Chemistry B, vol. 108, no. 7, pp. 2313-2322, 2004.

[9] Q. W. Jiang, G. R. Li, and X. P. Gao, "Highly ordered TiN nanotube arrays as counter electrodes for dye-sensitized solar cells," Chemical Communications, no. 44, pp. 6720-6722, 2009.

[10] J. Halme, M. Toivola, A. Tolvanen, and P. Lund, "Charge transfer resistance of spray deposited and compressed counter electrodes for dye-sensitized nanoparticle solar cells on plastic substrates," Solar Energy Materials and Solar Cells, vol. 90, no. 7-8, pp. 872-886, 2006. 

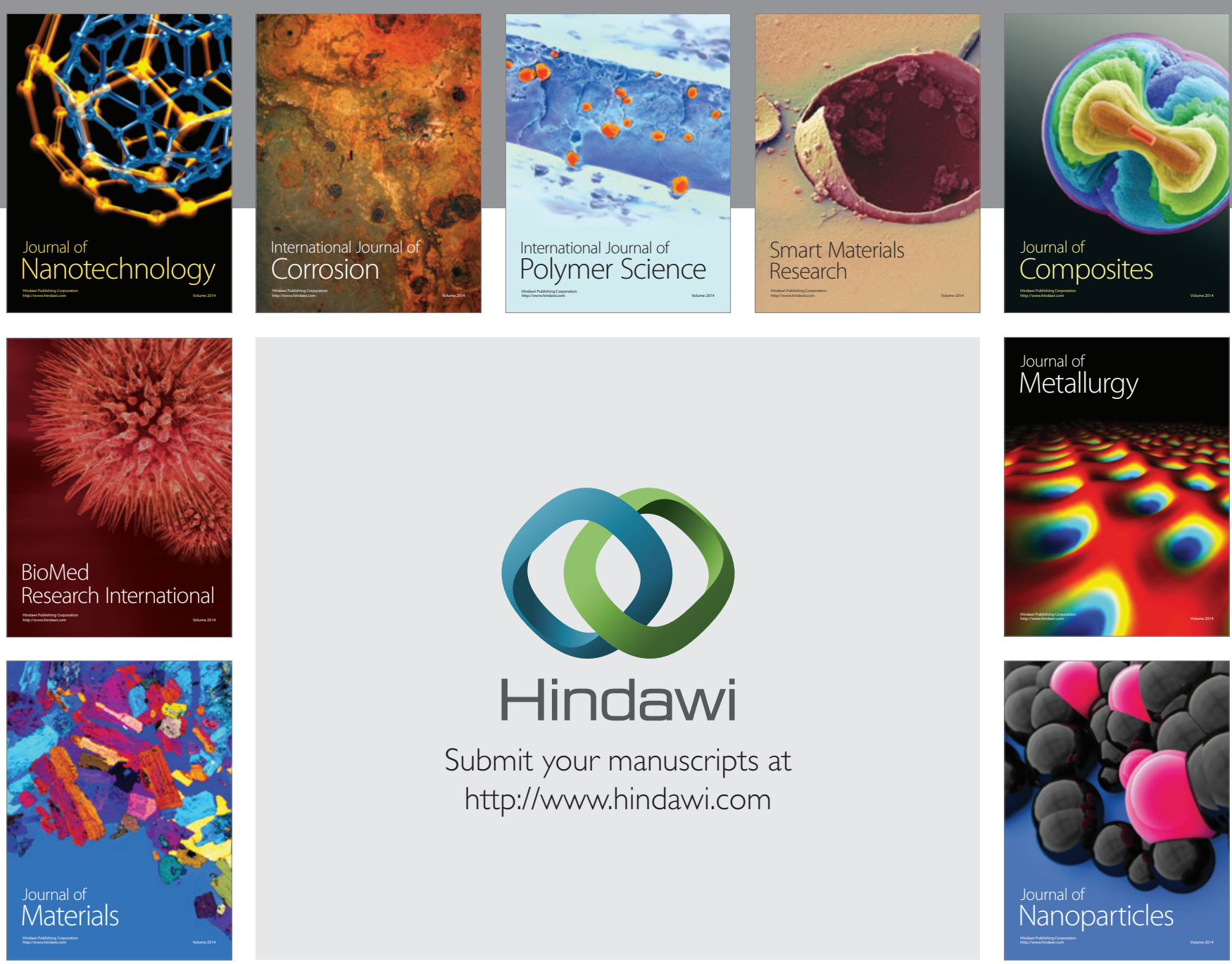

Submit your manuscripts at http://www.hindawi.com
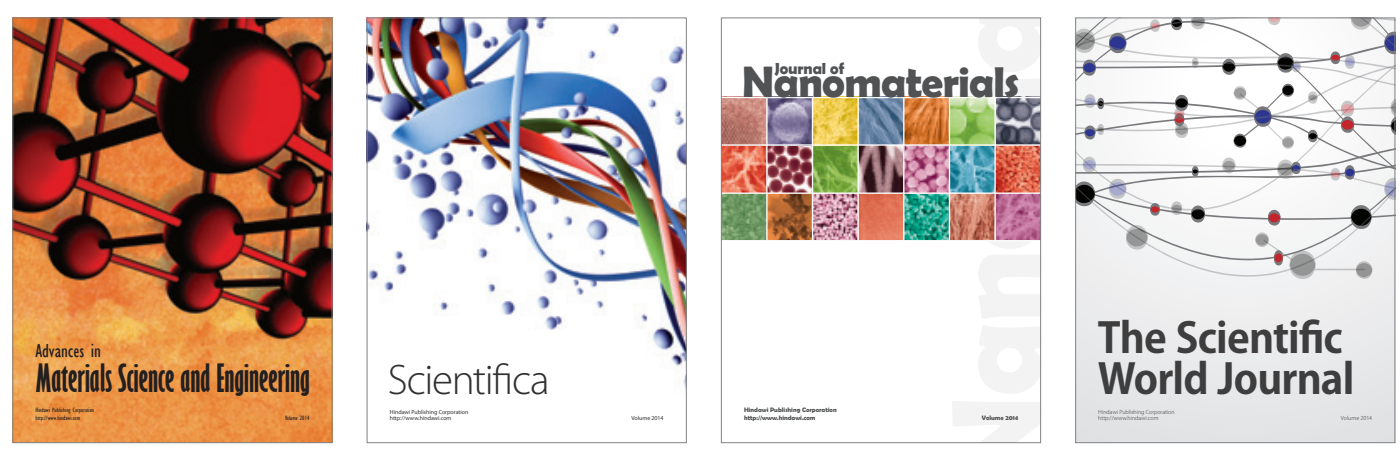

\section{The Scientific World Journal}
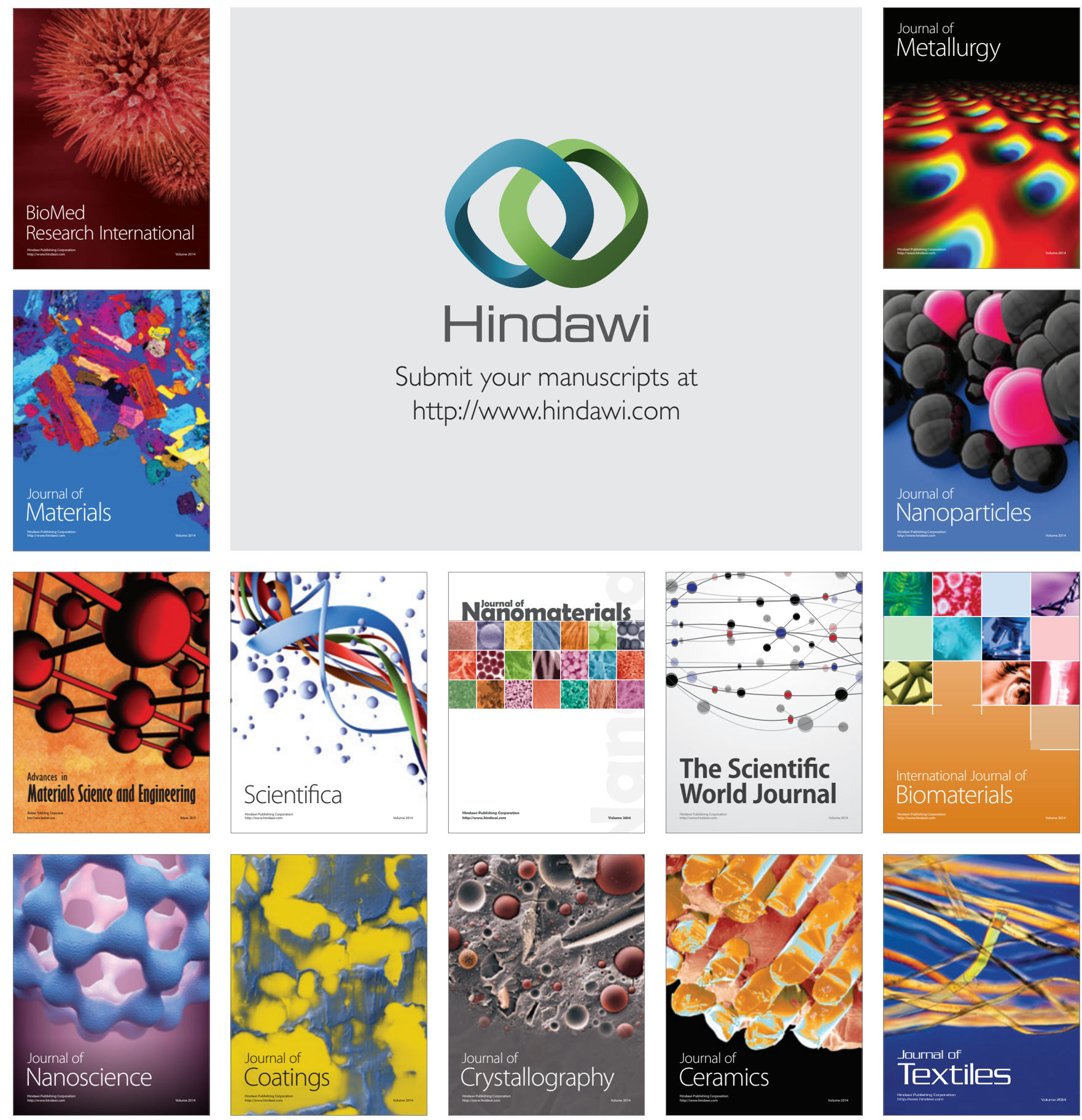